\title{
Consumption of energy drinks among Turkish University students and its health hazards
}

\author{
Arda Borlu', Belgin Oral², Osman Gunay ${ }^{3}$
}

\begin{abstract}
Objective: To determine the awareness, consumption patterns of energy drinks (ED) and health hazards among students at a Turkish University.

Methods: This cross-sectional descriptive study was conducted by questionnaire method between in 2017 among Erciyes University students. Total 1257 students from the Faculties of Medicine, Communication and Physical Education and Sports College participated in the study. Pearson chi-square test, binary logistic regressions were used for statistical analysis. $p<0.05$ values were considered significant.

Results: Students who tried at least once and consumed regularly ED were $52.5 \%$ and $15.7 \%$ respectively. Consuming regularly and trying ED were more common among students who were studying at Physical Education and Sports High school, male, smoking, alcohol consumer, doing regular physical activity. Mean age of students to start drinking ED was 15.1 years. Most common reason for ED consumption was; staying awake. Alcohol mixed energy drinks consumption rate was $37.6 \%$ among regular ED consumers. Most declared harmful effect was palpitation.

Conclusion: ED consumption among Erciyes University students was widespread. Students should be informed about EDs' hazards for health. Legal regulations regarding production, marketing and advertising of EDs must be reconsidered.
\end{abstract}

KEYWORDS: Energy Drink, University student, Alcohol mixed energy drink.

How to cite this:

doi: https://doi.org/10.12669/pjms.35.2.638

Borlu A, Oral B, Gunay O. Consumption of energy drinks among Turkish University students and its health hazards. Pak J Med Sci. 2019;35(2):537-542. doi: https://doi.org/10.12669/pjms.35.2.638

This is an Open Access article distributed under the terms of the Creative Commons Attribution License (http://creativecommons.org/licenses/by/3.0), which permits unrestricted use, distribution, and reproduction in any medium, provided the original work is properly cited.

1. Arda Borlu, M.D.

Assistant Professor

2. Belgin Oral, $M D$

HSU Ataturk Chest Diseases and Thoracic

Surgery Training and Research Hospital,

Ankara, Turkey.

3. Prof. Osman Gunay, M.D

1, 3: Erciyes University Medicine Faculty,

Public Health Department,

Kayseri, Turkey.

Correspondence:

Arda Borlu, M.D.

Assistant Professor

Erciyes University,

Medicine Faculty,

Public Health Department,

38030, Kayseri, Turkey.

E-mail: ardaborlu@gmail.com

* Received for Publication:

* Corrected and Edited:

* Accepted for Publication:
October 18, 2018

December 20, 2018

February 8, 2019

\section{INTRODUCTION}

Although EDs must be consumed carefully due to their contents, young people consume them widely, because of lack of knowledge and misleading advertisements. The most controversial content of ED is caffeine. Irritability, anxiety, restlessness, insomnia, tachycardia are common side effects of caffeine. ${ }^{1}$ Adverse effects are not expected with caffeine intake below $6 \mathrm{mg} / \mathrm{kg} /$ day for adults and $2.5 \mathrm{mg} / \mathrm{kg}$ for children. ${ }^{2}$ Body weight and personal caffeine sensitivity are predictors for toxic doses. ${ }^{3}$ The amount of caffeine per box of ED ranges from 72 to $294 \mathrm{mg}$. ${ }^{4}$ Hypertensive individuals are more susceptible to caffeine. ${ }^{5}$ As well as caffeine, ED includes taurine, guarana, ginseng, yohimbine, inositol, B vitamins, and glucuronolactone ${ }^{6}$ These substances can be stimulant, aphrodisiac, hepatotoxic, nephrotoxic and cardio toxic. ${ }^{7}$ 
Consumption of AMED (alcohol mixed ED) is often preferred because it causes the person to notice the effects of alcohol later and thus causes more and longer alcohol consumption. ${ }^{8}$ AMED is also common among university students. ${ }^{9,10}$ People consuming AMED were shown to be more frequently taking on risky behaviors. ${ }^{11}$

EDs are sometimes consumed instead of sports drinks which are produced to replace water and minerals after sports and do not contain stimulant substances. ${ }^{12}$

Determining the population at risk for ED consumption would be beneficial to develop strategies for reducing the misuses of ED among university students. The aim of this study was to determine the awareness, consumption patterns of ED and related health hazards among students at a Turkish University.

Table-I: Trying and Consuming Regular ED According to Characteristics of the Students.

\begin{tabular}{|c|c|c|c|c|c|c|c|c|c|c|}
\hline \multirow{2}{*}{ Characteristics } & \multirow{2}{*}{ Groups } & \multirow{2}{*}{$n$} & \multicolumn{2}{|c|}{ Tried ED } & \multirow{2}{*}{$X^{2}$} & \multirow{2}{*}{$p$} & \multicolumn{2}{|c|}{$\begin{array}{c}\text { Consuming regular } \\
E D\end{array}$} & \multirow{2}{*}{$X^{2}$} & \multirow{2}{*}{$p$} \\
\hline & & & Number & $\%$ & & & Number & $\%$ & & \\
\hline \multirow{3}{*}{ School } & Medicine & 632 & 247 & 39.1 & \multirow{3}{*}{116.63} & \multirow{3}{*}{$<0.001$} & 34 & 5.4 & \multirow{3}{*}{111.53} & \multirow{3}{*}{$<0.001$} \\
\hline & Communication & 311 & 182 & 58.5 & & & 67 & 21.5 & & \\
\hline & $\begin{array}{l}\text { Physical Educ- } \\
\text { ation and Sport }\end{array}$ & 314 & 237 & 75.5 & & & 96 & 30.6 & & \\
\hline \multirow{4}{*}{ School grade } & 1 & 346 & 170 & 49.1 & \multirow{4}{*}{7.71} & \multirow{4}{*}{0.052} & 52 & 15.0 & \multirow{4}{*}{2.78} & \multirow{4}{*}{0.427} \\
\hline & 2 & 335 & 192 & 57.3 & & & 58 & 17.3 & & \\
\hline & 3 & 304 & 171 & 56.3 & & & 40 & 13.2 & & \\
\hline & 4 & 272 & 133 & 48.9 & & & 47 & 17.3 & & \\
\hline \multirow{2}{*}{ Age (year) } & 19 and under & 334 & 145 & 43.4 & \multirow{2}{*}{16.72} & \multirow{2}{*}{$<0.001$} & 34 & 10.2 & \multirow{2}{*}{10.38} & \multirow{2}{*}{0.001} \\
\hline & 20 and over & 923 & 521 & 54.6 & & & 163 & 17.7 & & \\
\hline \multirow{2}{*}{ Gender } & Male & 614 & 394 & 64.2 & \multirow{2}{*}{60.29} & \multirow{2}{*}{$<0.001$} & 118 & 19.2 & \multirow{2}{*}{11.42} & 0001 \\
\hline & Female & 643 & 272 & 42.3 & & & 79 & 12.3 & & 0.001 \\
\hline & High & 525 & 275 & 52.4 & & & 86 & 16.4 & & \\
\hline Economic & Moderate & 676 & 362 & 53.6 & 0.22 & 0.895 & 99 & 14.7 & 2.12 & 0.347 \\
\hline & Poor & 56 & 29 & 51.8 & & & 12 & 21.4 & & \\
\hline & Never & 195 & 83 & 42.6 & & & 21 & 10.8 & & \\
\hline Doing physical & Irregular & 833 & 424 & 50.9 & 31.61 & $<0.001$ & 120 & 14.4 & 17.69 & $<0.001$ \\
\hline & Regular & 229 & 157 & 68.9 & & & 56 & 24.5 & & \\
\hline & Good & 894 & 482 & 53.9 & & & 144 & 16.2 & & \\
\hline $\begin{array}{l}\text { Self reported } \\
\text { health situation }\end{array}$ & Moderate & 318 & 158 & 49.7 & 1.83 & 0.400 & 43 & 13.5 & 2.73 & 0.256 \\
\hline & Poor & 45 & 24 & 53.3 & & & 10 & 22.2 & & \\
\hline Smoking & Yes & 271 & 196 & 72.3 & 5188 & $<0001$ & 80 & 29.5 & 5013 & $<0001$ \\
\hline 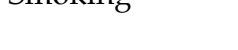 & No & 986 & 470 & 47.7 & 1.00 & 0.001 & 117 & 11.9 & 0.10 & $0.001+8$ \\
\hline Alcohol use & Yes & 233 & 167 & 71.7 & 4011 & $<0.001$ & 86 & 36.9 & 9761 & $<0001$ \\
\hline Aiconor use & No & 1024 & 499 & 48.7 & & & 111 & 10.8 & (9) & $<0.001$ \\
\hline Having chronic & Yes & 158 & 91 & 57.6 & 154 & 0215 & 30 & 19.0 & 148 & 0224 \\
\hline illness & No & 1099 & 575 & 52.3 & 1.04 & 0.213 & 167 & 15.2 & 1.40 & 0.224 \\
\hline Usino medicine & Yes & 105 & 62 & 59.0 & 167 & 0197 & 16 & 15.2 & 019 & 0890 \\
\hline 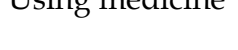 & No & 1152 & 604 & 52.4 & $1.0 \%$ & 0.197 & 181 & 15.8 & 0.19 & 0.090 \\
\hline Total & & 1257 & 666 & 53.0 & & & 197 & 15.7 & & \\
\hline
\end{tabular}




\section{METHODS}

This cross-sectional descriptive study was conducted by questionnaire method between April-June 2017. The universe of study was constituted by students at Erciyes University in 2016-2017 academic year. Sample size was calculated by assuming university students' EDs consumption rate of $50 \%$. Accepting confidence level $95 \%$, power $90 \%$ and tolerance value 0.05 , minimum sample size was calculated as 1049 . Students studying in first four years of Faculties of Medicine, Communication and Physical Education and Sports College (PESC) were included in the research (3954 students).

Ethical approval from Erciyes University Ethical Committee for Clinical Investigations and administrative permission from schools administrations were obtained for research.

Data were collected by the researchers using a questionnaire consisting of 41 questions.
The questions were prepared to determine the participants' socio-demographic characteristics, awareness and consumption patterns of ED. Students were visited in their classes by researchers, their consent were obtained and filled out the surveys themselves. Students who were not in the class during data collection were not included in this study. Total of 1257 students' data were evaluated.

Students who reported that they drank ED at least once in their lifetime were accepted as 'tried ED' and those who reported that they consume ED at least once a month were accepted as 'regular ED consumer'. Statistical analysis was performed on SPSS 15.0 at Windows program. Pearson's Chi-square test was used to compare independent variables between trying and regular ED consuming. Binary logistic regression analyses were used for determining related factors for tried ED and regular ED consumers. $\mathrm{p}<0.05$ were considered to be significant.

Table-II: Effect of Characteristics of Students on Trying EDs.

\begin{tabular}{|c|c|c|c|c|c|}
\hline \multirow{2}{*}{ Characteristics } & \multirow{2}{*}{ Groups } & \multirow{2}{*}{$n$} & \multicolumn{2}{|c|}{ Tried EDs } & \multirow{2}{*}{ OR (CI 95\%) } \\
\hline & & & Number & $\%$ & \\
\hline \multirow{3}{*}{ School } & Medicine & 632 & 247 & 39.1 & 1.00 \\
\hline & Communication & 311 & 182 & 58.5 & $2.02(1.48-2.73)$ \\
\hline & Physical Education and Sport & 314 & 237 & 75.5 & $3.92(2.78-5.52)$ \\
\hline \multirow{4}{*}{ School grade } & 1 & 346 & 170 & 49.1 & 1.00 \\
\hline & 2 & 335 & 192 & 57.3 & $1.31(0.91-1.88)$ \\
\hline & 3 & 304 & 171 & 56.3 & $0.95(0.62-1.45)$ \\
\hline & 4 & 272 & 133 & 48.9 & $0.85(0.55-1.32)$ \\
\hline \multirow{2}{*}{ Age (year) } & 19 and under & 334 & 145 & 43.4 & 1.00 \\
\hline & 20 and over & 923 & 521 & 54.6 & $1.12(0.77-1.63)$ \\
\hline \multirow{2}{*}{ Gender } & Female & 643 & 272 & 42.3 & 1.00 \\
\hline & Male & 614 & 394 & 64.2 & $2.18(1.68-2.82)$ \\
\hline \multirow{3}{*}{ Doing physical egzersize } & Never & 195 & 83 & 42.6 & 1.00 \\
\hline & Irregular & 833 & 424 & 50.9 & $1.39(0.98-1.98)$ \\
\hline & Regular & 229 & 157 & 68.9 & $1.88(1.19-2.98)$ \\
\hline \multirow{2}{*}{ Smoking } & No & 986 & 470 & 47.7 & 1.00 \\
\hline & Yes & 271 & 196 & 72.3 & $1.73(1.23-2.43)$ \\
\hline \multirow{2}{*}{ Alcohol use } & No & 1024 & 499 & 48.7 & 1.00 \\
\hline & Yes & 233 & 167 & 71.7 & $1.61(1.13-2.30)$ \\
\hline Total & & 1257 & 666 & 53.0 & \\
\hline
\end{tabular}




\section{RESULTS}

Percentages of trying ED and regular ED consumers were $52.5 \%$ and $15.7 \%$. Mean initial drinking age of students for ED was $15.1 \pm 3.2$ years. Factors that have the greatest effect on the first trial were; friends (51.8\%) and advertisements (30.9\%).

Students' school, age, gender, doing regular physical activity, smoking and using alcohol situations were found to be related to their both trying and regular ED consuming situations (Table-I). Logistic regression analyses of students' some characteristics and trying ED were given in Table-II while consuming regularly ED were given in Table-III.

Consumption characteristics of regular ED drinkers were as followings; most frequent consumption times; during meals $(26.9 \%)$, before sports $(19.3 \%)$, after sports $(15.2 \%)$; most frequent consumption places; café $(35.5 \%)$, home $(33.5 \%)$, sports fields $(27.9 \%)$; common important reasons for consumption; staying awake (15.8\%), being strong/fit (11.2\%) and habit (8.2\%).
AMED consumption rates were $11.1 \%$ among whole students and $37.6 \%$ among regular ED consumers. Among the regular ED consumers, 14.7 $\%$ had a chronic disease, $8.1 \%$ were using regular medication. The number of students who said that they had any harmful effect of ED was $6.3 \%$. The most commonly reported hazardous health effect was palpitation $(38.1 \%)$.

Only $18.0 \%$ of the students stated their level of knowledge self-evaluation about as sufficient, $65.6 \%$ of them knew ED and sports drinks were not the same. Sugar $(82.7 \%)$, caffeine $(72.9 \%)$ and taurine $(27.3 \%)$ were the most known substances in ED. Most of the students knew that EDs were harmful to pregnant women $(81.8 \%)$ and children $(81.7 \%)$. Less than half of the students $(40.3 \%)$ stated ED as harmful.

\section{DISCUSSION}

Half of the students consumed ED at least once in their lives. This rate was similar to other studies from Turkey; 46.5\% among Karadeniz Technical

Table-III: Effect of Characteristics of Students on Regular Consuming EDs.

\begin{tabular}{|c|c|c|c|c|c|}
\hline \multirow{2}{*}{ Characteristics } & \multirow{2}{*}{ Groups } & \multirow{2}{*}{$n$} & \multicolumn{2}{|c|}{ Regular EDs Drinkers } & \multirow{2}{*}{ OR (CI 95\%) } \\
\hline & & & Number & $\%$ & \\
\hline \multirow{3}{*}{ School } & Medicine & 632 & 34 & 5.4 & 1.00 \\
\hline & Communication & 311 & 67 & 21.5 & $4.15(2.59-6.66)$ \\
\hline & Physical Education and Sport & 314 & 96 & 30.6 & $5.43(3.41-8.65)$ \\
\hline \multirow{4}{*}{ School Grade } & 1 & 346 & 52 & 15.0 & 1.00 \\
\hline & 2 & 335 & 58 & 17.3 & $1.08(0.65-1.79)$ \\
\hline & 3 & 304 & 40 & 13.2 & $0.70(0.40-1.24)$ \\
\hline & 4 & 272 & 47 & 17.3 & $1.07(0.61-1.88)$ \\
\hline \multirow{2}{*}{ Age (year) } & 19 and under & 334 & 34 & 10.2 & 1.00 \\
\hline & 20 and over & 923 & 163 & 17.7 & $1.07(0.62-1.83)$ \\
\hline \multirow{2}{*}{ Gender } & Female & 643 & 118 & 19.2 & 1.00 \\
\hline & Male & 614 & 79 & 12.3 & $1.24(0.87-1.78)$ \\
\hline \multirow{3}{*}{ Doing sports } & Never & 195 & 21 & 10.8 & 1.00 \\
\hline & Irregular & 833 & 120 & 14.4 & $1.59(0.93-2.74)$ \\
\hline & Regular & 229 & 56 & 24.5 & $2.29(1.21-4.30)$ \\
\hline \multirow{2}{*}{ Smoking } & No & 986 & 117 & 11.9 & 1.00 \\
\hline & Yes & 271 & 80 & 29.5 & $1.52(1.02-2.26)$ \\
\hline \multirow{2}{*}{ Alcohol use } & No & 1024 & 111 & 10.8 & 1.00 \\
\hline & Yes & 233 & 86 & 36.9 & $3.22(2.18-4.77)$ \\
\hline Total & & 1257 & 197 & 15.7 & \\
\hline
\end{tabular}


University students ${ }^{13}$ and $48.3 \%$ among Hacettepe University students ${ }^{8}$ or from other countries; $54.6 \%$ in Puerto Rico ${ }^{14}$ and $51.8 \%$ in Taiwan. ${ }^{15}$

The regular ED consumption rate of students was lower than the others researched in the literature $(15.7 \%)$. This ratio was found to be $33 \%$ in a study conducted in Turkey ${ }^{8}, 51.0 \%$ in $\mathrm{USA}^{16}, 24.8 \%$ in Taiwan ${ }^{15}$ and $38 \%$ in Caribbean. ${ }^{17}$ These differences could be derived both from the various definitions of 'regular ED drinker' and in terms of having different cultural and economic characteristics of the groups participating in the studies.

The highest percentages of trying and regular consuming of ED were among PESC students. In other studies it was noticed that ED consumption was more common among PESC students than the others. ${ }^{8,13}$ This may be due to anticipation of a performance enhancing effect of ED. This idea is also supported by the higher rate of ED consumption among regular physical activity makers than the others in the study. The common misconception that 'EDs and sports drinks are the same' may also be increasing the ED consumption rate in physical activity makers. Also in our study, $34.4 \%$ of the participants did not knew ED and sports drinks were different.

Medical students were expected to have more knowledge about EDs' side effects and to avoid consuming them. As expected, medical students' drinking ED percentages were lower than others. Bulut et al. reported that medical students were the third among four surveyed faculties according to ED consumption frequency. ${ }^{13}$ At two other studies conducted in only Medicine faculties from Turkey and Pakistan, trying ED percentages was $32.6 \% 15$ and $42.9 \%$ respectively, similar to our study. ${ }^{18}$

Many studies have reported higher trying and regular consuming ED percentages in males than in females, in the literature as in our study. $8,13,17,19,20$ Men are more likely to participate in sporting activities and ED consumption is often associated with sporting activities. This may the reason to explain the relationship between men and ED. We noticed friend was the most important factor on first trial of ED drinking as determined in a study from Saudi Arabia. ${ }^{21}$

ED and alcohol consumptions were found to be related in many studies ${ }^{18,20}$ as in ours. Another risk about this topic is consumption of AmED. ED cause the effects of alcohol to occur later and by this way leading more alcohol consumption and more exposure to harmful effects of alcohol. In our study, $37.6 \%$ of regular ED drinkers consumed AmED.
AmED consumption percentages among regular EDs drinkers varies at the researches conducted in different countries; $28.2 \%$ in Turkey ${ }^{13}, 22.2 \%$ in Caribbean $^{17}, 38.0 \%$ in Puerto Rico. ${ }^{14}$

It was determined that $6.3 \%$ of regular ED drinkers had experienced a harmful effect due to ED, and the most frequent side effect was palpitation. Palpitation was marked as one of the most frequent side effects of ED at many studies. ${ }^{16,17}$ Experienced harmful effect rate in our study was lower than experienced at Reid et al. Study (62.2\% ). ${ }^{17}$ This may be due to our interrogation of side effects with an open-ended question and the inability of students to associate ED with side effects or inability to remember. Common reasons to consume ED were staying awake and being strong/fit. The common reasons determined to consume ED at other studies were; improving physical or academic performance, staying alert. $8,16,17$

Children are more susceptible to caffeine, ED may be toxic to certain organs, and may interact with certain medicines. For this reason, as stated in the Turkish Food Codex Regulation ED Communique ${ }^{22}$ consumption of ED are not recommended for people under the age of 18, with any chronic disease and drug users. But students' initial age for ED drinking was 15.1, like in another study from Taiwan (15.7 years). ${ }^{15}$ We also found that $14.7 \%$ of the regular ED consumers had chronic disease and $8.1 \%$ were using a drug. This results show us that students consume ED unconsciously as they don't avoid consuming ED even at risky situations.

\section{CONCLUSIONS}

ED consumption among Erciyes University students was quite widespread. This study determined some characteristics of the students who are at more risk to consume ED. Students need urgent education and awareness programs, especially about the EDs' potential hazard effects. Legal regulations regarding production, marketing and advertising of EDs' must be observed.

Funding: None.

Declaration of Interests: None declared.

\section{REFERENCES}

1. Ibrahim NK, Iftikhar R. Energy drinks: Getting wings but at what health cost? Pak J Med Sci. 2014;30(6):1415-1419. doi: 10.12669/pjms.306.5396.

2. Nawrot P, Jordan S, Eastwood J, Rotstein J, Hugenholtz A, Feeley M. Effects of caffeine on human health. Food Addit Contam. 2003;20(1):1-30. doi: 10.1080/0265203021000007840. 
3. Higdon JV, Frei B. Coffee and health: a review of recent human research. Crit Rev Food science Nutr. 2006;46(2):101123. doi: $10.1080 / 10408390500400009$

4. Heneman K, Zidenberg-Cherr S. Nutrition and health info sheet: Energy Drinks. 2007. Accessed date: 05.03.2018

5. Hartley TR, Sung BH, Pincomb GA, Whitsett TL, Wilson MF, Lovallo WR. Hypertension risk status and effect of caffeine on blood pressure. Hypertension. 2000;36(1):137141. doi: 10.1161/hyp.36.1.137.

6. Reissig CJ, Strain EC, Griffiths RR. Caffeinated energy drinks - a growing problem. Drug Alcohol Depend 2009;99(1):1-10. doi: 10.1016/j.drugalcdep.2008.08.001.

7. Dikici S, Aydin LY, Kutlucan A, Ercan N. What do we know about energy drinks? Dicle Med J. 2012;39(4):609-613.

8. Attila S, Cakir B. Energy-drink consumption in college students and associated factors. Nutrition. 2011;27(3):316322. doi: 10.1016/j.nut.2010.02.008.

9. Miller KE. Alcohol mixed with energy drink use and sexual risk-taking: Casual, intoxicated, and unprotected sex. J Caffeine Res. 2012;2(2):62-69. doi: 10.1089/jcr.2012.0015.

10. O'Brien MC, McCoy TP, Rhodes SD, Wagoner A, Wolfson $\mathrm{M}$. Caffeinated cocktails: energy drink consumption, highrisk drinking, and alcohol-related consequences among college students. Acad Emerg Med. 2008;15(5):453-460. doi: 10.1111/j.1553-2712.2008.00085.

11. Woolsey C, Waigandt A, Beck NC. Athletes and energy drinks: reported risk-taking and consequences from the combined use of alcohol and energy drinks. J Appl Sport Psychol. 2010;22(1):65-71. doi: 10.1080/10413200903403224.

12. Schneider MB, Benjamin HJ. Sports drinks and energy drinks for children and adolescents: are they appropriate? Pediatrics. 2011;127(6):1182-1189.

13. Bulut B, Beyhun NE, Topbas M, Can G. Energy drink use in university students and associated factors. J Comm Health. 2014;39(5):1004-1011. doi: 10.1007/s10900-014-9849-3.

14. Cabezas-Bou E, De Leon-Arbucias J, Matos-Vergara N, Alvarez-Bagnarol Y, Ortega-Guzman J, Narvaez-Perez K, et al. A Survey of Energy Drink Consumption Patterns Among College Students at a Mostly Hispanic University. J Caffeine Res. 2016:6(4);154-162. doi: 10.1089/jcr.2016.0011.

15. Chang YJ, Peng CY, Lan YC. Consumption of Energy Drinks among Undergraduate Students in Taiwan: Related Factors and Associations with Substance Use. Int J Envir Res Pub Health. 2017;14(9):954. doi: 10.3390/ijerph14090954.
16. Malinauskas BM, Aeby VG, Overton RF, Carpenter AT, Barber Heidal K. A survey of energy drink consumption patterns among college students. Nutr J. 2007;6(1):35. doi: 10.1186/1475-2891-6-35.

17. Reid SD, Ramsarran J, Brathwaite, Lyman S, Baker A, $\mathrm{D}^{\prime}$ Andra $\mathrm{C}$, et al. Energy drink usage among university students in a Caribbean country: Patterns of use and adverse effects. J Epidemiol Glob Health. 2015;5(2):103-116. doi: 10.1016/j.jegh.2014.05.004.

18. Aslam HM, Mughal A, Edhi MM, Saleem S, Rao MH, Aftab A, et al. Assessment of pattern for consumption and awareness regarding energy drinks among medical students. Arch Pub Health. 2013;71(1):31. doi: 10.1186/20493258-71-31.

19. Berger LK, Fendrich M, Chen HY, Arria AM, Cisler RA. Sociodemographic correlates of energy drink consumption with and without alcohol: results of a community survey. Addictive behaviors. 2011;36(5):516-519. doi: 10.1016/j.addbeh.2010.12.027.

20. Rahamathulla MP. Prevalence, side effects and awareness about energy drinks among the female university students in Saudi Arabia. Pak J Med Sci. 2017;33(2):347-352. doi: 10.12669 / pjms.332.12084

21. Ministry of Food, Agriculture and Livestock: Turkish Food Codex Energy Drinks Notification (2017/4) Official Gazette number: 30110. 30 June 2017 doi: 2017/06/20170930-23.

\section{Author's Contribution:}

AB: Planned the study, prepared and finally approved the manuscript.

BO: Collected and entered the data, drafted and finally approved the manuscript.

OG: Selected the topic, planned the study, analyzed the data, edited and finally approved the manuscript. 